\title{
Health Risks in Our Environment: Urban Slum Youth' Perspectives Using Photovoice in Kampala, Uganda
}

\author{
Charles Ssemugabo*(D), Sarah Nalinya, Grace Biyinzika Lubega (D, Rawlance Ndejjo and David Musoke \\ Department of Disease Control and Environmental Health, School of Public Health, Makerere University College \\ of Health Sciences, Kampala 7072, Uganda; nalsarah4@gmail.com (S.N.); gracelubega45@gmail.com (G.B.L.); \\ rndejjo@musph.ac.ug (R.N.); dmusoke@musph.ac.ug (D.M.) \\ * Correspondence: cssemugabo@musph.ac.ug; Tel.: +256-779-625-182
}

Citation: Ssemugabo, C.; Nalinya, S.; Lubega, G.B.; Ndejjo, R.; Musoke, D. Health Risks in our Environment: Urban Slum Youth' Perspectives Using Photovoice in Kampala, Uganda. Sustainability 2021, 13, 248. https://doi.org/10.3390/su13010248

Received: 29 September 2020 Accepted: 23 December 2020 Published: 29 December 2020

Publisher's Note: MDPI stays neutral with regard to jurisdictional clai$\mathrm{ms}$ in published maps and institutional affiliations.

Copyright: (C) 2020 by the authors. Licensee MDPI, Basel, Switzerland. This article is an open access article distributed under the terms and conditions of the Creative Commons Attribution (CC BY) license (https:// creativecommons.org/licenses/by/ $4.0 /)$.

\begin{abstract}
Due to increasing urbanization, many people find themselves living in slums that expose them to several health risks. We explored urban health risks that fall short of the planetary boundaries in an urban slum in Kampala, Uganda using photovoice. We selected, trained, and assigned ten youth (five females and five males) to take photos on urban health risks. The photographs were discussed, and transcripts were analyzed based on the doughnut economics model using content analysis in NVivo 12. Environments and actions of slum dwellers expose them to health risks, and cause them to live at the edge of planetary boundaries. Environmental sanitation challenges, including solid and liquid waste management, excreta management, and food hygiene and safety expose slum dwellers to risks at the edge of the lower boundary of the planet. Urban conditions expose slum dwellers to poor physical infrastructure, undesirable work conditions, pollution, and health and safety challenges. Crime, violence, and substance use were also viewed as vices that make slum environments dangerous habitats. On the other hand, practices like inhabiting wetlands and using biomass fuels in addition to traffic fumes expose slum dwellers to effects associated with living above the planetary boundaries. Urban youth reflected on health risks that have immediate effects on their health and day-to-day living. Urbanization, especially in low resource settings, needs to be cognizant of the ensuing risks to health and thus ensure sustainable growth.
\end{abstract}

Keywords: planetary boundaries; ecological ceiling; social foundation; empowerment; photographs

\section{Introduction}

Globally, more people live in urban rather than rural areas. Over $55 \%$ and $43 \%$ of the world's and Africa's population, respectively, live in urban areas [1]. The proportion of world urbanites has drastically risen from 30\% in 1950 and is projected to reach $68 \%$ by 2050 [1]. Uganda has also experienced an upward trend of urbanization, with 57\% of the population living in urban centers [2]. Despite the opportunities and benefits that urbanization presents, it leads to environmental degradation, which is associated with several urban health risks. The risks include contamination of water, food, and soil, which result from limited access to improved water and sanitation [3]. The reliance on solid fuels including biomass to meet basic energy needs such as cooking and boiling water, coupled with the overcrowded and poorly ventilated houses, expose urban communities to indoor air pollutants that increase the risk of pneumonia and chronic pulmonary obstructive disease [3]. In addition, overcrowding and uneven terrain in slums are responsible for a high incidence of unintentional injuries, especially among children [4].

Over the years, Kampala has remained the only city in Uganda with a semblance of sufficient social services and economic opportunities, albeit being originally built on seven major hills with swamps occupying the lowlands. Many people have moved from rural to urban areas, resulting in slum development and degradation of wetlands in Kampala. Out of the 1,516,210 people that live in Kampala [2], approximately 53.6\% $(812,688)$ live in slummy wetlands [5]. The rapid slum development has resulted in several 
health hazards including flooding and waterlogging, indiscriminate fecal sludge disposal, indiscriminate solid waste disposal, and uneven and unsafe topography, especially for children [6,7]. Consequently, this has resulted in limited access to safe drinking water, increased disease vectors, especially mosquitoes that spread malaria, disease outbreaks such as cholera and typhoid, injuries, and malnutrition [6,8-10]. The unsustainable and unplanned developments of the housing, transport, and food systems in these slums have also resulted in other health risks such as: air pollution (indoor and ambient), unhealthy diets, unsafe drinking water, indiscriminate solid and liquid waste management, flooding, inadequate durability of housing, low security of tenure, overcrowdedness, and infectious disease such as HIV/AIDs. However, these risks are not entirely due to poor urban planning by the authorities but also residents' poor organization and limited understanding of how they can address their problems.

Urbanization is often associated with opportunities and development, including overall increased economic growth and gross domestic product (GDP). As such, there is a public perception that the semblance of the planetary social foundations only exists in urban centers and, as such, has resulted in rural-urban migration. Examples of such social foundations include food security, health, education, housing, energy, social equity, gender equality, political voice, income, peace, and justice [11]. This unplanned ruralurban migration has resulted in the disruption of some planetary boundaries not limited to land conversion, biodiversity loss, freshwater withdrawals, climate change, and air pollution [11,12]. According to Kate Raworth, humanity's 21st century greatest challenge is to meet the needs of all (social foundations) within the means of the planet (ecological ceiling) using doughnut economics [13,14]. The model calls for thriving within the environmentally safe and socially just space between the social foundation and the ecological ceiling of the doughnut economics model [13]. While some slum communities have built resilient structures and drainage channels and put measures in place to prevent and control the spread of diseases, there are many more health risks that existing in these settings. In order to understand the health risks that compromise the planetary boundaries of slum dwellers, we used photovoice among youth living in slums to explore how urban youth view the health risks that they face in their communities.

Photovoice is a community-based participatory research method often used by people with limited power due to poverty and social class such as slum dwellers to identify aspects of their environment and share them with others while mobilizing them to take action $[15,16]$. Photovoice has been found to empower communities, build capacity of participants, facilitate peer learning, and promote ownership [17]. Photovoice has previously been used to elicit voices/ideas of disadvantaged population segments including women, youth, community health workers, amongst others [18-21]. While critical, youth voices are often ignored in the planning and solving of community problems. In fact, youth who are defined by the Africa Youth Charter as every person between the age of 15 and 35 years make up 35\% of Uganda's population [22], which is arguably the largest segment of the population. Urban youth in Kampala are confronted with employment, shelter, food, water, violence and crime, and substance use risks, amongst others, and thus, it is their responsibility to ensure that urbanization is carried out in a planned and healthy manner that minimizes risks that potentially affect their health. The use of photovoice among youth to identify and mobilize the community to address their challenges empowers the largest segment of the population to take action.

\section{Methods}

\subsection{Study Design}

This was a qualitative study that used Photovoice, a community-based participatory research methodology. Photovoice was used to empower youth to identify and take action on the health risks they face in their community. Photovoice has been found to empower population segments such as youth and women to address community challenges [18,23]. The study used ten youth (five females and five males) to take photographs of urban health 
risks and mitigations measures over a period of 3 months. This paper specifically presents findings related to urban health risks. The photos taken were discussed fortnightly, and a total of five meetings were held to discuss photographs taken.

\subsection{Study Area and Setting}

The study was carried out in Kasubi Parish, Lubaga Division in Kampala, the capital city of Uganda. Kasubi Parish is comprised of nine zones and a population of 384,386 people [2]. Kasubi parish is a residential area with several small businesses, uneven topography, and network of roads transecting through it. The majority of the population in Kasubi are youth aged 15 to 35 years. Kasubi is located on a steep slope that connects to a reclaimed wetland, and this has several gullies. The major economic activity is large and medium trade in food, lodging, and merchandise, amongst others. Kasubi has a Public Health facility (Health Center IV and several private for-profit health facilities where the public seeks health care. Kasubi is also closely located to Mulago national referral hospital and several other private not-for-profit hospitals including Mengo and Lubaga hospitals. Kasubi is largely made of permanent structures with a few temporary structures. The researchers have previously implemented a community water, sanitation, and hygiene (WASH) improvement project in Kasubi parish, during which they discovered that residents observed reflected on several health risks that affect the population.

\subsection{Selection of Study Participants}

The youth that participated in the study were mobilized and invited by local leaders based on their ability to read and write, as well as gender. Youth were considered to be between the ages of 15 and 35 years [22] based on the African Youth Charter definition, which was more encompassing and favored the demographic structure of the area. A meeting was organized for the invited youth from which five males and five females were recruited after clearly explaining to them the proposed research to enable them to make an informed decision regarding participation or not. The criteria for selecting the ten participants included selecting a diverse range of men and women in terms of age, marital status and geographical location in the area. This helped ensure a wide variety of perspectives from the participants, as was the case in previous Photovoice studies carried out $[20,21]$. All the youth that participated in this study were aged between 18 and 35 years (Table 1).

Table 1. Demographics of study participants.

\begin{tabular}{ccccccc}
\hline Participant Number & Zone & Age & Gender & Education Level & Occupation & Marital Status \\
\hline 1 & Kawaala I & 28 & Male & Tertiary (University) & Accountant & Single \\
2 & Kasubi II & 18 & Female & Secondary (advanced level) & Student & Single \\
3 & Kawaala I & 22 & Female & Tertiary (Diploma) & Student & Single \\
4 & Kasubi I & 23 & Female & Secondary (advanced level) & Unemployed & Single \\
5 & Kasubi II & 29 & Male & Tertiary (University) & Business & Engaged \\
6 & Kasubi II & 22 & Male & Secondary (advanced level) & Business & Single \\
7 & Kasubi I & 27 & Male & Tertiary (University) & Electrician & Single \\
8 & Kasubi I & 30 & Female & Secondary (advanced level) & Unemployed & Single \\
9 & Kasubi II & 27 & Male & Secondary (advanced level) & Business & Single \\
10 & Kasubi IV & 35 & Female & Secondary (ordinary level) & Business & Single \\
\hline
\end{tabular}

\subsection{Training Workshop}

After recruiting the participants, a one-day training workshop was conducted to orient them on the scope of the study including urban health risks and mitigation measures, use and care of cameras, and ethics in photography. The workshop was held at a primary school in the community and was facilitated by the researchers. To minimize potential risks to participants, during the training we discussed several issues, including how to 
approach people and getting consent before taking their pictures. During the training, each youth was provided with a camera, a notebook and pen to use during the research. The notebook was to take note of any issues related to the research that may not be captured on camera especially if consent was denied.

\subsection{Photography Assignment}

At the end of the training, youth were asked to use the cameras provided to them by the research team to capture aspects and situations in their community that have potential to cause health risks and the mitigation measures undertaken by communities to address them. Participants were given 3 months for taking the pictures given urban health risks manifest frequently in slum communities. A follow-up visit one week after commencement of photography was carried out to provide early support to the teams and address any challenges faced by the participants. Regular support supervision of the participants by the research team was carried out during the entire period of photography.

\subsection{Discussing Photos and Data Analysis}

All photos taken by youth during the period of the study were presented and discussed in five fortnightly meetings. The meetings were held between the youth and researchers and lasted between 3 to $4 \mathrm{~h}$. One researcher facilitated the meeting while the other took notes and provided other logistical support, such as transferring photographs to the laptop. Meetings with the youth served as a means for discussion of photographs using a participatory approach. From the photographs taken, each participant was asked to select the photographs they felt are most significant to the themes of the study. The selected photographs were projected to a screen to facilitate a discussion. Each photographer was given a chance to analyze and discuss the photographs they took. After each photograph had been presented, other youth were given a chance to share their opinion about it. After exhausting all the photographs, the youth had taken in the previous fortnight, they were given a chance to present any other issues that they could not capture on camera. Any emerging issues from previous meetings were presented to the youth after all photographs had been discussed for clarification.

The meetings were conducted in the local language (Luganda) and proceedings audio recorded and transcribed verbatim by one of the researchers. After translating the transcripts to English, NVivo version 12 was used to organize, codify, and analyze the data using thematic content analysis. Coding was done deductively using Kate Raworth Doughnut economics theory [11] and inductively based on the words and phrases that appeared more often as analyzed with the NVivo software. Related codes were organized into meaningful categories based on recurring ideas and the Doughnut economics model [11]. Categories were grouped into major themes and presented under the two major grouping of the Doughnut economic model that is the social foundation shortfall and the ecological ceiling overshoot. All the themes were described and illustrated with direct quotes and photographs.

\subsection{Ethical Considerations}

Ethical approval to conduct the study was obtained from Makerere University School of Public Health Higher Degrees, Research and Ethics Committee, and Uganda National Council for Science and Technology. All youth provided written informed consent before taking part in the study after explaining to them the proposed research including the anticipated risks and potential benefits. Based on the researcher's past photovoice experience and other published photovoice studies [24,25], the youth obtained verbal consent from members of the community before taking their photographs. While obtaining consent before photography, individuals were informed that the photos taken will be used during research team meetings for discussion. All photographs and discussion notes and/or transcripts were handled confidentially, and no photographs taken during this study were 
used for any form of dissemination without consent from the photographer and individuals involved in them.

\section{Results}

From May to July 2019, five meetings were held with 10 youth (5 males and 5 females) residing in the slum community to discuss a total of 671 photos. The findings are organized and presented based on the Kate Raworth doughnut economics theory (Figure 1). Under the ecological ceiling, urban youth identified environmental sanitation, poor physical infrastructure, undesirable work conditions, poor food hygiene and safety, unsafe sex practices and environments, environmental pollution as their major health risks. Land conversion and air pollution were the only urban health risk that overshoot the ecological ceiling, and thus causing major health challenges.

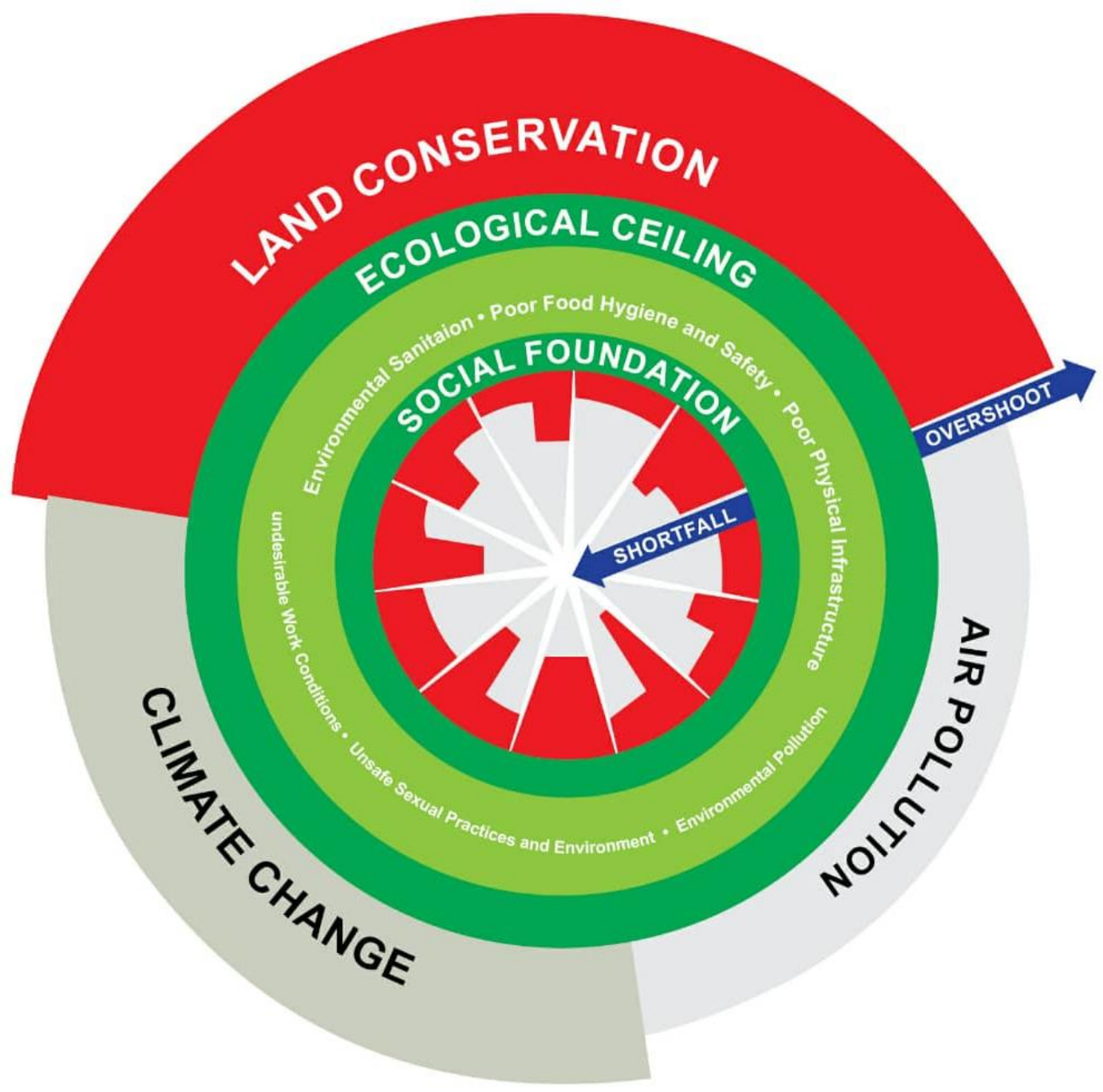

Figure 1. Kate Raworth's doughnut economics model demonstrating urban health risks in slums.

\subsection{Social Foundation Shortfalls}

\subsubsection{Environmental Sanitation}

The study established that most health risks were as a result of environmental factors that can result in disease transmission in urban settlements. Urban youth identified indiscriminate solid waste disposal (Figure 2) as a major risk to their health. Indiscriminate 
disposal of all forms of waste without segregation was said to attract houseflies and increase the chances of disease transmission.

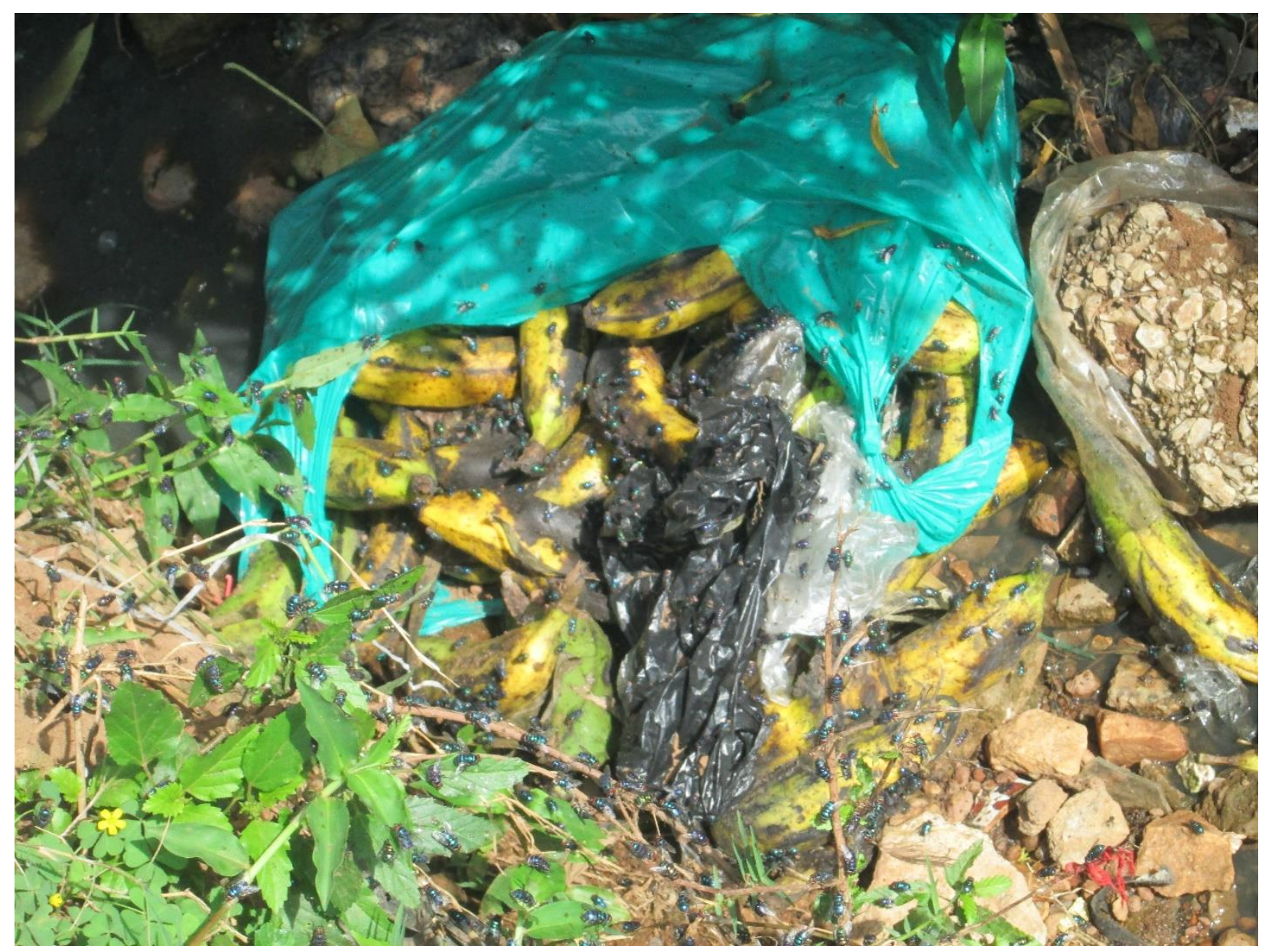

Figure 2. Indiscriminately disposed solid waste attracting houseflies.

The indiscriminate disposal and accumulation of waste was attributed to inadequate solid waste collection vessels and the delays in collection of waste by the garbage trucks.

"Garbage is collected at one point as people wait for the garbage truck to pick it. The truck often delays for days and the garbage accumulates all over the place while attracting flies. It makes the place unhygienic and spreads diseases." (Photographer 4, Female, 23 years)

From the photos, slum dwellers are challenged with indiscriminate release of fecal matter (Figure 3). Many latrine facilities in slums were constructed with a provision to release fecal matter into the nearby drainage channel, which is done whenever it rains. Community members were also said to defecate in polythene bags, which were later indiscriminately disposed of and/or urinate in the drainage channels.

Wastewater from kitchens and bathrooms is also indiscriminately disposed of. Many bathrooms are not connected to a drainage system such as a septic tank or soak away pit. The foul water used nuisances such as flies that are injurious to people's health.

"Someone was bathing in the bathroom, but the wastewater is moving straight into the stormwater channels. The wastewater is stagnated in the stormwater channel and thus could cause diarrheal diseases, cholera especially if children play in that kind of water" (Photographer 6, male, age 22) 
It was established that blocked drainage channels presented key health risks to slum dwellers. The youth highlighted that slum dwellers indiscriminately disposed solid waste into the drainage channels causing their blockage and consequently flooding. The flooded water acts as a breeding place for mosquitoes (Figure 4) that are responsible for malaria spread in the community.

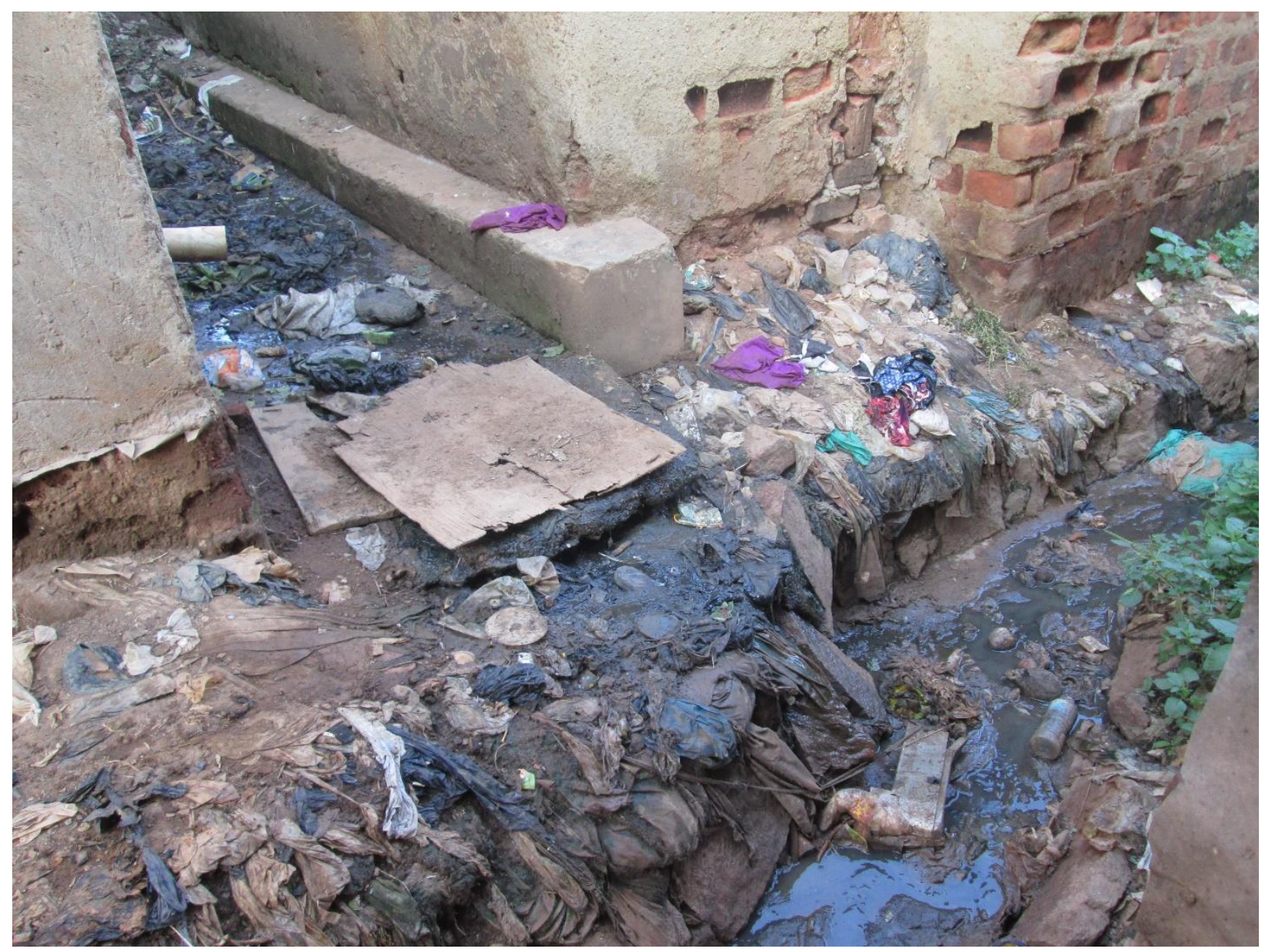

Figure 3. Indiscriminate release of fecal matter into the drainage channels. 


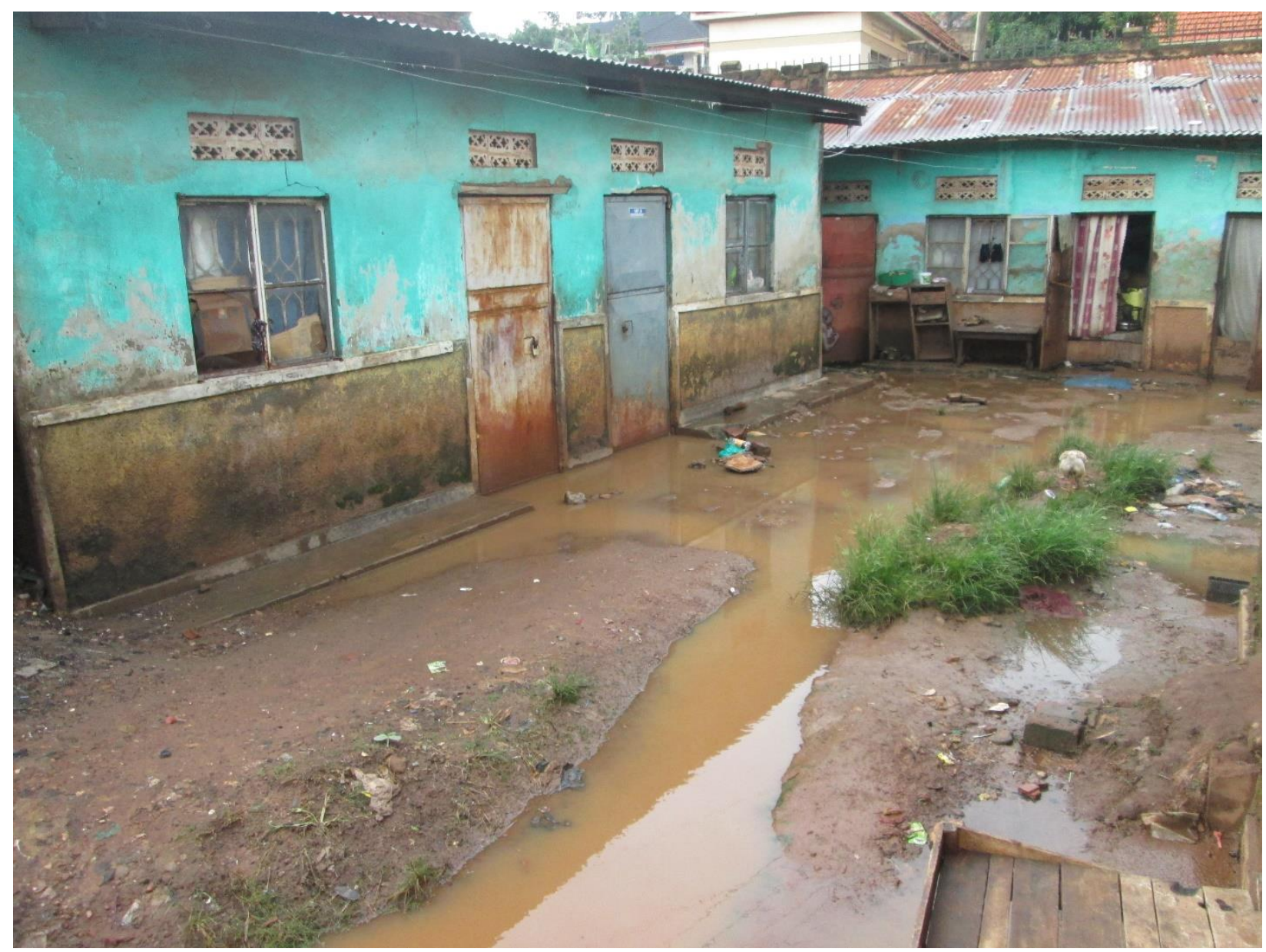

Figure 4. Flash floods in urban slum households and compound.

\subsubsection{Poor Physical Infrastructure (Housing)}

Regarding physical infrastructure, many facilities within the slum were either old or in-need of repair or renovation in order to play their role. Youth mentioned loose old wooden bridges as a great risk to the urban slum dwellers. In fact, some drainage channels were said to have no bridges. Some houses and, in particular, latrines structures were dilapidated, putting the inhabitants at risk of injuries and death.

"If the responsible persons/owners of these house do not either remove or renovate them.

These houses are a nuisance. In fact, at night, a person can hide there and attack you.

There are a unforeseen danger" (Photographer 7, male, 27 years)

The study also established that there is a lot of congestion with in the slum areas that results in poor sanitation and hygiene conditions. From Figure 5, many waste collection sites and latrines or septic tanks could not be reached by solid waste or cesspool emptiers. The overcrowding can also result in the spread of communicable diseases like HIV and respiratory tract infections. 


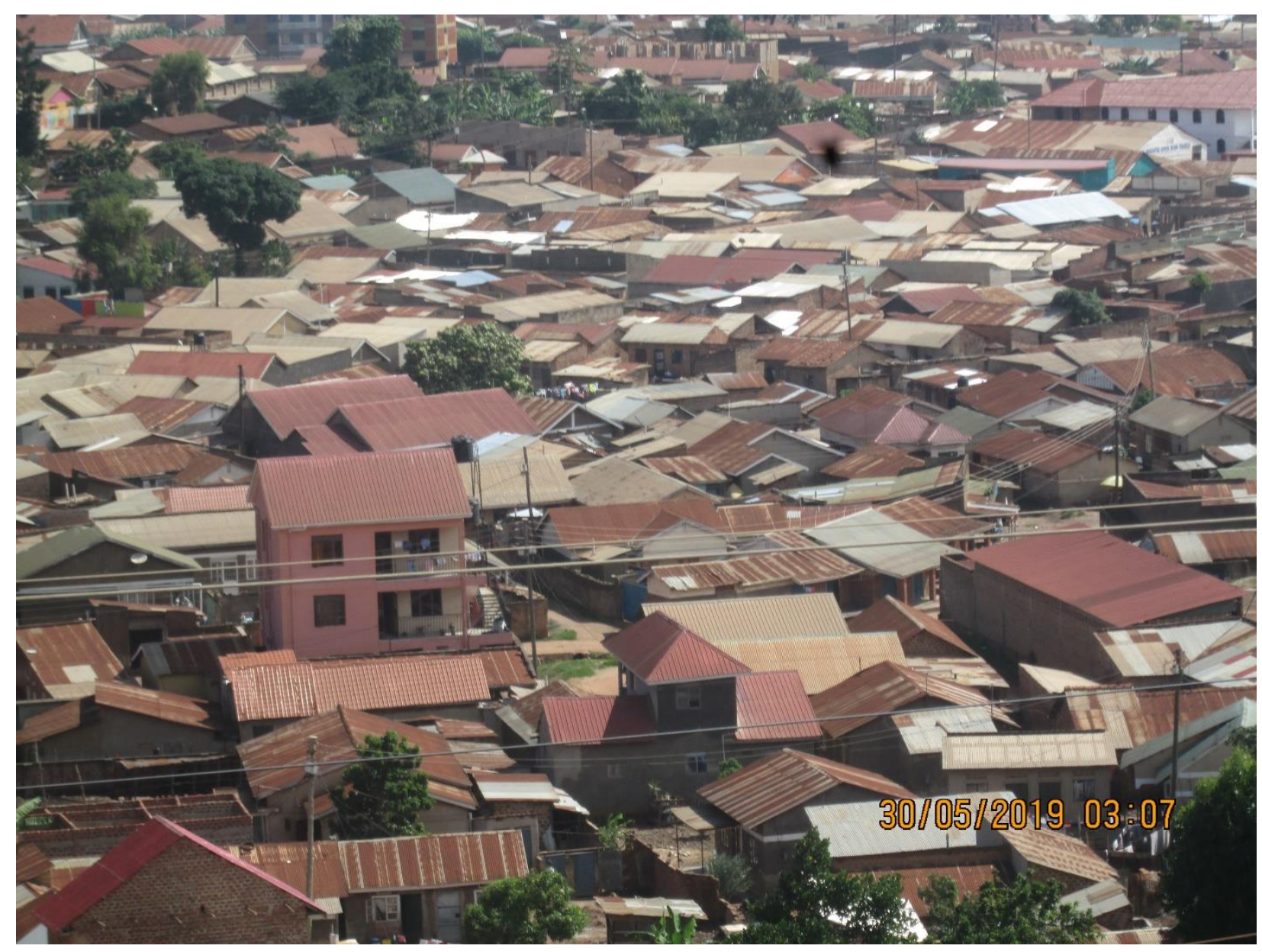

Figure 5. Overview photo of the study community showing overcrowding.

\subsubsection{Undesirable Work Conditions}

It was observed that many urban youths face work-related challenges. Urban youth mentioned that many slum dwellers engage in work such as carrying very heavy loads that exposes them to ergonomic hazards. Others are engaged in work roles that expose them to dust and other particulate matter without wearing the recommended protective gears and thus might eventually develop respiratory illnesses.

"This man was carrying building materials from a ground to first floor on that building site. He was carrying three heavy blocks every round, which were too much weight for him. He is likely to develop chest complications that could result in death" (Photographer 7, male, aged 27)

Urban youth also revealed that many slum dwellers are unemployed and thus resort to theft and alcohol.

"This man had attacked a neighbor to rob them and they cut him with a panga. Immediately, a mob beat him to death. It is not a good thing for people to take justice into their hands, especially when the court has not participated" (Photographer 9, male, aged 27)

\subsubsection{Poor Food Hygiene and Safety}

The study established that poor food safety is one of the health risks. Youth reported several practices that comprise improper food hygiene and safety. Among these included: selling food over drainage channels and in dusty environments, cooking food in polythene 
bags, restaurants located near stormwater channels with foul water, slaughtering birds and animals in unclean spaces (Figure 6), selling unboiled drinking water.

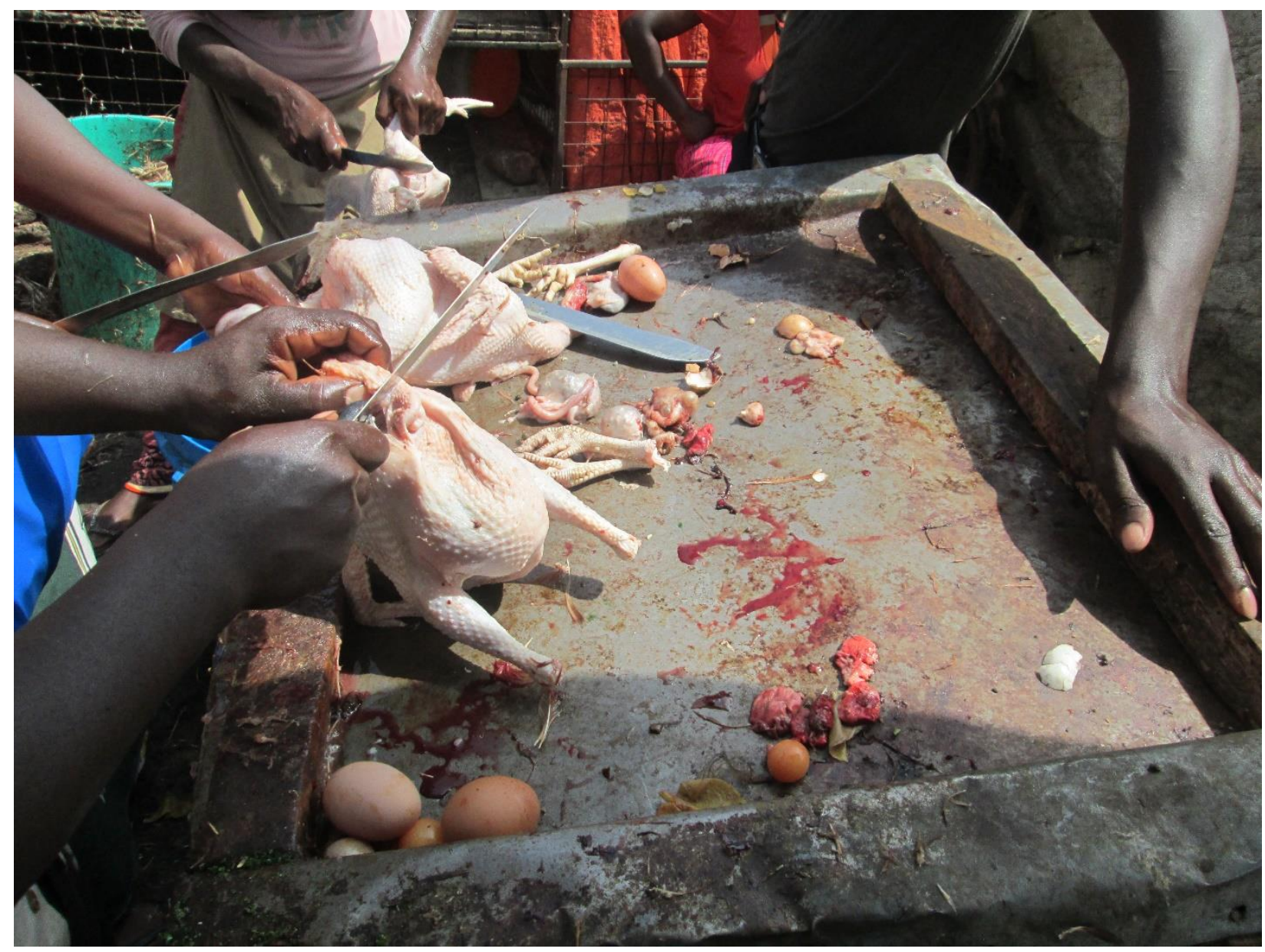

Figure 6. Community members slaughtering chicken on a dirty surface.

\subsubsection{Unsafe Sexual Practices and Environments}

Urban youth said that there is increased spread of communicable diseases due to the congestions and the spread of sexual acts. They mentioned that many people engage in unprotected sex and contract HIV and other sexually transmitted diseases. Youth also mentioned the practice of drinking local brew (Malwa) while sharing the straw that is common in slums, yet it can fuel spread of other communicable disease such as TB and hepatitis $\mathrm{B}$.

"While drinking "malwa", many people use one pot with many straws and yet some people have poor drinking habits. They put back saliva into the pot, and these days, we have hepatitis $B$ on the rise, which is transmitted through saliva and sweat. Yet, you can't know how is infected or they can also get Tuberculosis (TB)" (Photographer 8, female, aged 30)

From the photos, urban youth revealed many unsafe environments that could put the lives of slum dwellers at risk. The physical environment had many deeply dug trenches including drainage channels and gullies that can result in unintentional injuries. Many homes had no playing space for children and thus played along the roads or near drainage channels or on highly raised verandas. In fact, urban youth said that some children had drowned in the drainage channels. Urban youth also mentioned that they were many stray animals, especially dogs that presented a risk to urban residents. 
"This man was trying to save this child who had fallen into the drainage channel. If this man wasn't fast enough, this child would have died due to the surface runoff just like the other child who was hit by the house" (Photographer 1, male, aged 28)

Urban slum residents reported experiencing high levels of crime and violence including theft. Urban youth said that crime and violence are perpetuated by use of drugs and other substances, poverty, and several dark corners within slums.

"This man was beaten because he was a thief. He had attacked a neighbor who had a panga and he cut him. Immediately there was mob justice and they beat him to death. It is not good for people to take justice into their hands yet there are courts of law" (Photographer 9 , male, age 27)

Urban youth said that their colleagues drink alcohol during the day. They spend most of their money on alcohol, which weakens and prevents them from working and, consequently, they resort to stealing. They also get involved in other criminal vices like rape.

"The youth drink alcohol during the day. This man was so dirty and his trouser had changed color from black to brown. He was drinking alcohol on his way back home and fell into a trench. He hit his mouth and lost his teeth but also suffered other injuries"

(Photographer 6, male, age 22)

\subsection{Ecological Ceiling Overshoot}

\subsubsection{Land Conversion}

It was revealed that some slum settlements are located in areas that were swamps and thus meant for holding drained stormwater. Urban youth mentioned that several houses that were constructed in swamps flood when it rains and put the lives of the inhabitants at risk of death or contraction of communicable diseases.

"This house was built in a swampy area where there is a lot of stagnant water. So, whether it rains or not, there is water. In case the people who reside in the house don't use mosquito nets they will contact malaria given that the area has good breeding ground for the mosquitos" (Photographer 3, female, aged 22)

Land conversion is made worse by the lack of and/or the blockage of drainage channels with waste. No or blocked drainage channels escalate the challenge of flooding (Figure 7) and thus put the lives of slum dwellers at risk.

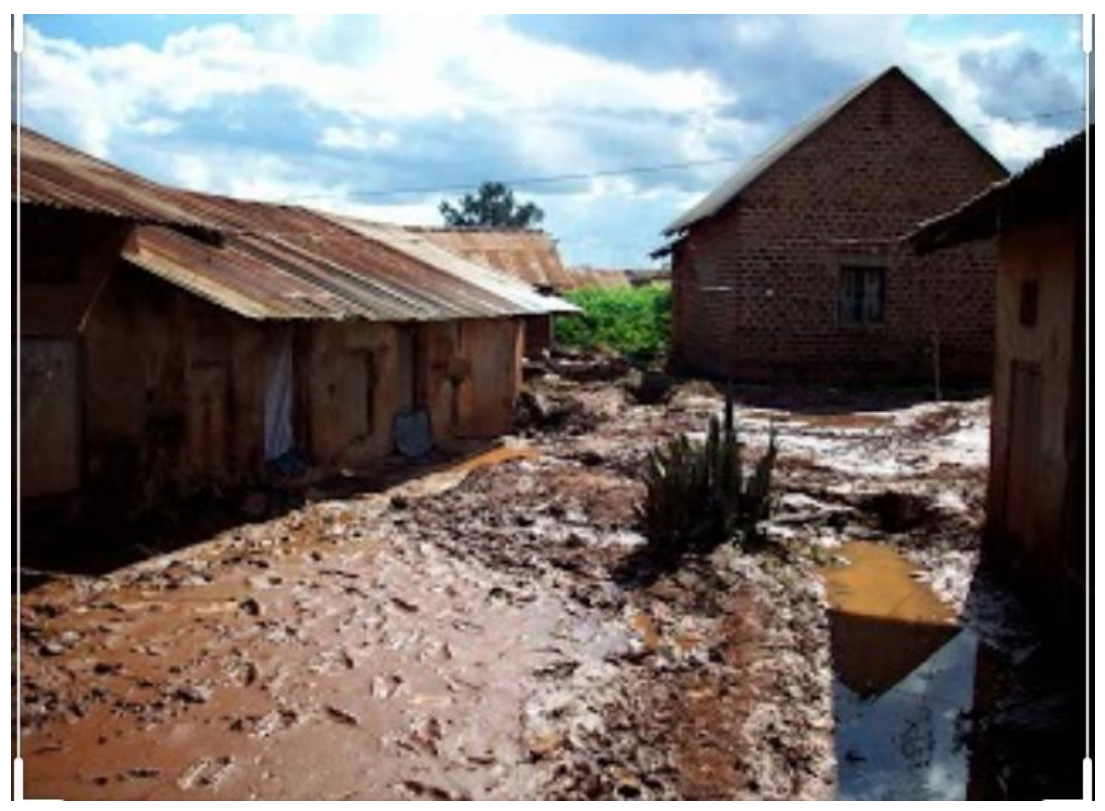

Figure 7. Houses built in a wetland and prone to flooding. 


\subsubsection{Environmental Pollution}

From the photos, it is clear that urban slum residents live in highly polluted environments. Urban youth said that there are high levels of air pollution due to traffic. The slum is located along the highway with many feeder roads that are heavily congested with traffic most hours of the day causing resulting in heavy release of carbon monoxide and other air pollutants. Many households used biomass fuels like firewood and charcoal that results in indoor and outdoor pollution in some instances. Frequent burning of solid waste also contributes to the existing levels of air pollution.

"She uses firewood to cook cassava. She will inhale the smoke that comes from the firewood.

These inhaled air pollutants can affect her lungs" (Photographer 1, male, aged 28)

It was also established that contaminated water from the urban settlement uphill drains into low-lying spring water. Communities collect drinking water from the heavily contaminated spring waters.

"This spring is in the valley while settlements are above it. All the contaminated water flowing from the houses such as the bathroom wastewater ends up into the spring making the spring water unfit for human consumption" (Photographer 7, male, age 27)

Urban communities also face a challenge of noise pollution. Youth said that there are many sources of noise that pollute the environment. Among these sources includes construction, traffic, market/business, and churches. Daily exposure to high wavelength noise presents risks of temporary or permanent hearing loss, stress, amongst others.

"This is a storey building. The whole of the lower level are rentals, and the upper level is a church. Churches have overnights, which exposes the people on the lower floors to noise depriving them of sleep" (Photographer 10, female, age 22)

\section{Discussion}

Our study explores urban health risks that fall short of, or overshoot the planetary boundaries in an urban slum in Kampala, Uganda using photovoice, reflecting on how to ensure development happens in a more sustainable fashion. The lack of adequate basic facilities exposes slum dwellers to indiscriminate solid and liquid waste management, food hygiene and safety, and excreta management challenges. The poorly planned and congested environments also expose poor physical infrastructure, undesirable work environments, pollution, and unsafe sex practices and environments. Low-resource settings also result in increased crime, violence, and substance use vices that put slum dwellers lives at risk. Slum dwellers practices of settling in wetlands and relying on biomass fuels in order to survive also present dire health risks. Our findings demonstrate that unplanned urban environments have devastating immediate and long-term implications for the lives of their inhabitants and, consequently, the environment.

From our study, it was evident that environmental sanitation issues, including solid waste and wastewater disposal and excreta disposal, were the most common health risks that slum urban dwellers faced. This is not surprising given most of the slums are characterized by low-resource facilities, including those for sanitation and hygiene promotion. Many households can neither afford proper solid waste collection containers nor solid waste collection fees. Relatedly, cesspool emptiers are expensive, which forces slum dwellers to resort to indiscriminate disposal of solid waste into drainage channels. Our findings are similar to those from studies carried in the same community that found a worrying sanitation status [26,27]. Environmental sanitation is a very expensive venture for lowresourced households in slums, yet it has overriding health implications. Community or individual failure to observe proper environmental sanitation breaks Kate Ragwort's social foundation of the doughnut, and thus might lead to premature death.

Poor food hygiene and safety were also identified as common urban health risks. Given the levels of congestion in slum communities, it is expected that many food safety standards and guidelines are neglected in homes, markets, and restaurants. Our findings 
corroborate with those from a study carried out in Nairobi Kenya slums where E. coli was found in several food samples on the market [28]. The poor levels of food hygiene in slums could be responsible for the high prevalence of diarrheal disease related to food infections [29]. While the greatest concern of the world is food shortage, food hygiene and safety also present enormous challenges to the many slum dwellers. Unsafe food is responsible for many diarrheal disease infections and loss of productive hours. So, in order to ensure sustainable development, there is a need to promote food hygiene and safety and consequently prevent food-related infections in these communities.

Poor physical structures were also identified as a key health risk to slum dwellers' health. The majority of slum dwellers live in rented households. Despite the lack of resources to improve their structures, they do not have the power to renovate them. In addition, many slum areas are located in low-lying areas that are swampy with high water tables that are inhabited illegally and, as such, are afraid of constructing permanent structures. Our findings corroborate reviews that identified physical structure challenges as very key in slum development [30], attributing this to lack of secure land or housing tenure and densely packed structures built with substandard or flammable materials [31]. In fact, the poor infrastructure magnifies the other health risks such as respiratory conditions experience by slum dwellers.

Slum communities in Kampala boost the most populated zones/parishes/divisions in Uganda (ref). In fact, the population density in these areas is said to be over 378,000 per square kilometer $[31,32]$. The high population density is attributed to the overcrowding. Our findings revealed that overcrowding is one of the health risks that slum dwellers experience. In fact, it is said to be the cause of many other health risks, including spread of communicable diseases like respiratory tract infections, HIV, and STIs, amongst others [33]. Our findings are in line with those from a review carried out by Elsey and colleagues from Nepal that reported overcrowding and poor ventilation as key risks that often resulted in respiratory disease, gastrointestinal disease, and burn injuries [34,35]. Therefore, in order to reduce health risks in urban slums, there is need to decongest the slum communities through construction of storey structures that can accommodate more households while creating more space.

The poor socio-economic conditions leave slums dwellers with no option but blue color jobs including carrying heavy loads at construction sites, cleaning roads, amongst others [36]. Often, such blue color expose employees to conditions that are hazardous to their health. Our study findings revealed that many slum dwellers work in dusty and polluted environments but are not provided with adequate personal protective equipment. Our findings also revealed that slum conditions including poor infrastructure, overcrowding and inadequate access to sanitation and hygiene exposes slum dwellers to several communicable diseases such as respiratory diseases, diarrhea, and others, intentional and unintentional injuries, and poor access to health care services. Our findings corroborate with findings from a review of slum health challenges in LMICs [31]. Many health-related challenges in slums cut across several realms including physical, social, economic, and political. Therefore, improving slum health requires a holistic approach with the other stakeholders in the planetary boundaries, including urban planners, community development specialist, community members, and policy makers, amongst others.

Youth said that pollution that is air, noise and water pollution was among the health risks that slum dwellers grapple with on a day-to-day basis. This is expected, given the contextual challenges that slum dwellers face. Kasubi slum and many other slums in Uganda are located near the central business district and thus experience high levels of pollution from heavy traffic. Slum dwellers also use biomass fuels for cooking in addition to burning solid waste, contributing to indoor and outdoor pollution. Noise from markets, business adverts aired on loudspeakers, traffic, and churches puts the lives of slum dwellers that reside in this rather residential area at risk of its auditory and nonauditory effects. Given the indiscriminate disposal of solid and liquid waste, including excreta, low-lying area water sources that a certain percentage of the slum dwellers rely on, 
easily get contaminated. While noise and water pollution effects fall within the planetary boundaries, according to Raworth's model, the effect of air pollution often overshoot it. Our findings are similar to those from a study carried out Nairobi that found high levels of air pollutants $\left(\mathrm{PM}_{2.5}\right)$ in slums due to use of biomass fuels. Therefore, reduction of pollution, especially air pollution in slum areas in important in reducing both the shortand long-term effects associated with it.

Many slum settlements inhabit marginal areas including riverbanks, steep slopes, dumping grounds, and wetlands [30], yet such environments are unsafe and present risks to human health. In fact, slums are often found within and/or at the outskirts of cities' marginal areas especially steep slopes, dumping areas, and wetlands [30]. Our study revealed that slums are located in low-lying wetlands and thus are liable to many associated risks including flooding and vector-borne diseases. This is not surprising given that Kampala is located on over seven hills and thus many slum settlements are found in the low-lying areas that are largely reclaimed swamps with high water tables. The night population of Kampala increase from 1.5 million in 2014 [2] to approximately 2 million in 2018 [37], the increment is largely attributed to the growing slum population. The increase in slum populations might be attributed to reclamation of wetlands. The conversion of wetlands meant to hold stormwater and support drainage and treatment of water into a habitable land presents several risks to slum dwellers and the entire environment in the short and long-term, including environmental degradation and climate change. Given the nature of settlements and location, a holistic approach is required to improve the conditions of leaving.

We used photovoice to empower urban youth to take action about their community problems. Youth make over $30 \%$ of Uganda's population [37] and thus, it is imperative that they take full responsibility for their community challenges. Often, youth marginally engage in community initiatives, including those geared towards solving community problems. The use of a community-based participatory methodology is one way to get them to actively participate in community development projects. In addition to solving community challenges, youth gain new skills, build partnerships, and present ideas to their community leaders. In fact, urban youth reported sensitization, counseling, mobilization of community for action as activities they participated in triggered by their involvement in the photovoice study. Our findings are similar to a study that used information and communication technologies to economic empower rural youth in aboriginal communities in Australia. Studies that have used photovoice have indeed also demonstrated that youth can promote health by identifying community-based health challenges and take action through advocacy while gaining new skills and knowledge [23]. We anticipate that urban youth will be proactive in identifying and solving community problems as a result of participating in this study. This anticipated change in the study communities has not been documented with other study designs. Therefore, youth empowerment initiatives should be explored using participatory rapid assessment tools and methods like photovoice.

A major strength of this study is that it used photovoice to explore urban youth's perspective on the health risks they face in their communities. The use of photovoice ensured that participants take lead in identifying urban health risks but also get empowered to understand and address them. However, our study was carried out in one parish in Kampala, its findings might not be generalizable to other slums in Uganda and geographical contexts. Nonetheless, our study highlights urban health risks that make slum dwellers fall short or overshoot the planetary boundaries. Therefore, there is a need for more participatory research to understand the interaction between the various health risks and identify priorities for interventions.

\section{Conclusions}

Urban youth identified slum dwellers practices and conditions including environmental sanitation, poor food hygiene and safety, poor physical infrastructure, environment pollution, and unsafe sexual practices and environments using photovoice as shortfalls 
that force them to live in undesirable situations that are below the planetary expectations. On the other hand, photovoice revealed that settling in swampy areas and using biomass fuels, amongst others, exposes slum dwellers to adverse health risks while degrading the environment. Therefore, there is a need for all stakeholders to ensure that urban areas are adequately planned to enable sustainable growth.

Author Contributions: C.S. and D.M. conceptualized the study and was involved in data collection, analysis and manuscript writing. S.N., G.B.L. and R.N. were involved in data collection, analysis and manuscript writing. All authors have read and agreed to the published version of the manuscript.

Funding: This study was funded by Makerere University School of Public Health under the Small Grants Programme.

Institutional Review Board Statement: Ethical approval to conduct the study was obtained from Makerere University School of Public Health Higher Degrees, Research and Ethics Committee, and Uganda National Council for Science and Technology.

Informed Consent Statement: Written informed consent was obtained from youth after explaining to them the proposed research including the anticipated risks and potential benefits of participating in the study. The youth obtained verbal consent from members of the community before taking their photographs. While obtaining consent before photography, individuals were informed that the photos taken will be used during research team meetings for discussion.

Data Availability Statement: The data that support the findings of this study are available on request from the corresponding author, [CS].

Conflicts of Interest: The authors declare that they have no competing interests.

\section{References}

1. United Nations Department of Economic and Social Affairs, Population Division. World Urbanisation Prospects; United Nations: New York, NY, USA, 2018.

2. UBOS. National Population and Housing Census 2014 Provisional Results; Uganda Bureau of Statistics Kampala: Kampala, Uganda, 2014.

3. Kjellstrom, T.; Friel, S.; Dixon, J.; Corvalan, C.; Rehfuess, E.; Campbell-Lendrum, D.; Gore, F.; Bartram, J. Urban Environmental Health Hazards and Health Equity. J. Urban Health Bull. N. Y. Acad. Med. 2007, 84, 86-97. [CrossRef] [PubMed]

4. Ssemugabo, C.; Mukama, T.; Halage, A.A.; Paichadze, N.; Gibson, D.G.; Kobusingye, O. Incidence and characteristics of unintentional injuries among children in a resource limited setting in Kampala, Uganda. Int. J. Inj. Control Saf. Promot. 2018, 25, 449-457. [CrossRef] [PubMed]

5. United Nations. Millenium Development Goals Indicators: The Official United Nations Site for MDGs Indicatprs. Available online: http://mdgs.un.org/unsd/mdg/Metadata.aspx?IndicatorId=32 (accessed on 20 December 2018).

6. Isunju, J.B.; Christopher Garimoi, O.; Jaco, K. Hazards and vulnerabilities among informal wetland communities in Kampala, Uganda. Environ. Urban. 2015, 28, 275-293. [CrossRef]

7. David, S.; Sheridan, B. Editorial: The full spectrum of risk in urban centres: Changing perceptions, changing priorities. Environ. Urban. 2017, 29, 3-14. [CrossRef]

8. Myers, S.S. Land Use Change and Human Health. In Integrating Ecology and Poverty Reduction: Ecological Dimensions; Ingram, J.C., DeClerck, F., Rumbaitis del Rio, C., Eds.; Springer: New York, NY, USA, 2012; pp. 167-186.

9. Legros, D.; McCormick, M.; Mugero, C.; Skinnider, M.; Bek'Obita, D.D.; Okware, S.I. Epidemiology of cholera outbreak in Kampala, Uganda. East Afr. Med. J. 2000, 77, 347-349. [CrossRef]

10. WHO. Typhoid fever-Uganda. In Global Alert Response-Disease Outbreak News; World Health Organisation: Geneva, Switzerland, 2015.

11. Raworth, K. A Safe and Just Space for Humanity. Can We Live within the Doughnut? 2012. Available online: https://www. oxfam.org/en/research/safe-and-just-space-humanity (accessed on 20 December 2018).

12. Hossain, M.S.; Ifejika Speranza, C. Challenges and opportunities for operationalizing the safe and just operating space concept at regional scale. Int. J. Sustain. Dev. World Ecol. 2020, 27, 40-54. [CrossRef]

13. Ross, F. Kate Raworth-Doughnut Economics: Seven Ways to Think Like a 21st Century Economist (2017). Reg. Bus. Stud. 2019, 11, 81-86. [CrossRef]

14. Schokkaert, E. Review of Kate Raworth's Doughnut Economics. London: Random House, 2017, 373 pp. Erasmus J. Philos. Econ. 2019, 12, 125-132. [CrossRef]

15. Castleden, H.; Garvin, T. Modifying Photovoice for community-based participatory Indigenous research. Soc. Sci. Med. 2008, 66, 1393-1405. [CrossRef]

16. Wang, C.; Burris, M.A. Photovoice: Concept, methodology, and use for participatory needs assessment. Health Educ. Behav. Off. Publ. Soc. Public Health Educ. 1997, 24, 369-387. [CrossRef] 
17. Catalani, C.; Minkler, M. Photovoice: A review of the literature in health and public health. Health Educ. Behav. Off. Publ. Soc. Public Health Educ. 2010, 37, 424-451. [CrossRef] [PubMed]

18. Wang, C.C. Youth Participation in Photovoice as a Strategy for Community Change. J. Community Pract. 2006, 14, 147-161. [CrossRef]

19. Musoke, D.; Ssemugabo, C.; Ndejjo, R.; Molyneux, S.; Ekirapa-Kiracho, E. Ethical practice in my work: Community health workers' perspectives using photovoice in Wakiso district, Uganda. BMC Med. Ethics 2020, 21, 68. [CrossRef] [PubMed]

20. Musoke, D.; Ssemugabo, C.; Ndejjo, R.; Ekirapa-Kiracho, E.; George, A.S. Reflecting strategic and conforming gendered experiences of community health workers using photovoice in rural Wakiso district, Uganda. Hum. Resour. Health 2018, 16, 41. [CrossRef]

21. Musoke, D.; Ekirapa-Kiracho, E.; Ndejjo, R.; George, A. Using photovoice to examine community level barriers affecting maternal health in rural Wakiso district, Uganda. Reprod. Health Matters 2015, 23, 136-147. [CrossRef]

22. African Union Commission. African Youth Charter; African Union Commission: Addis Ababa, Ethiopia, 2009.

23. Necheles, J.W.; Chung, E.Q.; Hawes-Dawson, J.; Ryan, G.W.; Williams, S.B.; Holmes, H.N.; Wells, K.B.; Vaiana, M.E.; Schuster, M.A. The Teen Photovoice Project: A pilot study to promote health through advocacy. Prog. Community Health Partnersh. Res. Educ. Action 2007, 1, 221-229. [CrossRef]

24. Kovacic, M.B.; Stigler, S.; Smith, A.; Kidd, A.; Vaughn, L.M. Beginning a partnership with PhotoVoice to explore environmental health and health inequities in minority communities. Int. J. Environ. Res. Public Health 2014, 11, 11132-11151. [CrossRef]

25. Kwiringira, J.; Atekyereza, P.; Niwagaba, C.; Günther, I. Descending the sanitation ladder in urban Uganda: Evidence from Kampala Slums. BMC Public Health 2014, 14, 624. [CrossRef]

26. Ssemugabo, C.; Wafula, S.T.; Ndejjo, R.; Osuret, J.; Musoke, D.; Halage, A.A. Characteristics of sanitation and hygiene facilities in a slum community in Kampala, Uganda. Int. Health 2020. [CrossRef]

27. Adhiambo, M.; Nyamari, J.; Imungi, J.I. Food Hygiene Conditions and Microbial Contamination of Minimally Processed Fruits in Central Ward, Nairobi County. Int. J. Sci. Res. Publ. 2017, 7, 137.

28. Wandolo, M.A. Food safety and hygiene practices in the informal outlets (a case study of food kiosks in Kibera slums, Nairobi). In Public Health; Kenyatta University: Nairobi, Kenya, 2011.

29. Mahabir, R.; Crooks, A.; Croitoru, A.; Agouris, P. The study of slums as social and physical constructs: Challenges and emerging research opportunities. Reg. Stud. Reg. Sci. 2016, 3, 399-419. [CrossRef]

30. Unger, A.; Riley, L.W. Slum health: From understanding to action. PLoS Med. 2007, 4, e295. [CrossRef] [PubMed]

31. UBOS. Statistical Abstract 2018; Uganda Bureau of Statistics Kampala: Kampala, Uganda, 2018.

32. Zerbo, A.; Delgado, R.C.; González, P.A. Vulnerability and everyday health risks of urban informal settlements in Sub-Saharan Africa. Glob. Health J. 2020, 4, 46-50. [CrossRef]

33. Elsey, H.; Manandah, S.; Sah, D.; Khanal, S.; MacGuire, F.; King, R.; Wallace, H.; Baral, S.C. Public Health Risks in Urban Slums: Findings of the Qualitative 'Healthy Kitchens Healthy Cities' Study in Kathmandu, Nepal. PLoS ONE 2016, 11, e0163798. [CrossRef] [PubMed]

34. Corburn, J.; Vlahov, D.; Mberu, B.; Riley, L.; Caiaffa, W.T.; Rashid, S.F.; Ko, A.; Patel, S.; Jukur, S.; Martínez-Herrera, E.; et al. Slum Health: Arresting COVID-19 and Improving Well-Being in Urban Informal Settlements. J. Urban Health 2020, 97, $348-357$. [CrossRef] [PubMed]

35. Bird, J.; Montebruno, P.; Regan, T. Life in a slum: Understanding living conditions in Nairobi's slums across time and space. Oxf. Rev. Econ. Policy 2017, 33, 496-520. [CrossRef]

36. Singleton, G.; Rola-Rubzen, M.F.; Muir, K.; Muir, D.; McGregor, M. Youth empowerment and information and communication technologies: A case study of a remote Australian Aboriginal community. GeoJournal 2009, 74, 403. [CrossRef]

37. Lofton, S.; Norr, K.F.; Jere, D.; Patil, C.; Banda, C. Developing Action Plans in Youth Photovoice to Address Community-Level HIV Risk in Rural Malawi. Int. J. Qual. Methods 2020, 19, 1609406920920139. [CrossRef] 